\title{
Prevalence of Depression in Pre-Dialytic Chronic Kidney Disease Patients Attending at a Tertiary Care Hospital in Bangladesh
}

\author{
A. K. M. Shahidur Rahman 1*, Mohammad Shamsul Ahsan'2, Mohammad Kamrul Ahsan3, \\ A. B. M. Mobasher Alam4, Tanvir Rahman', Shahida Mullah', Md. Mustafizur Rahman7, \\ Salahuddin Feroz ${ }^{8}$, Amir Mohammad Kaiser'9, Md. Shariful Haque ${ }^{10}$
}

\author{
${ }^{1}$ Department of Nephrology, Bangabandhu Sheikh Mujib Medical University (BSMMU), Dhaka, Bangladesh \\ ${ }^{2}$ Department of Psychiatry, Bangabandhu Sheikh Mujib Medical University (BSMMU), Dhaka, Bangladesh \\ ${ }^{3}$ Holy Family Red Crescent Medical College Hospital (HFRCMCH), Dhaka, Bangladesh \\ ${ }^{4}$ Department of Nephrology, Rangpur Medical College Hospital (RMCH), Rangpur, Bangladesh \\ ${ }^{5}$ Department of Nephrology, United Hospital Limited, Dhaka, Bangladesh \\ ${ }^{6}$ Department of Medicine, Sarkari Karmachari Hospital, Dhaka, Bangladesh \\ ${ }^{7}$ Department of Nephrology, Sheikh Hasina Medical College, Tangail, Bangladesh \\ ${ }^{8}$ Sheikh Hasina National Institute of Burn and Plastic Surgery, Dhaka, Bangladesh \\ ${ }^{9}$ Department of Nephrology \& Dialysis, Gonoshaystha Somazvittik Medical College and Gonoshaystha Nagar Hospital, Dhaka, \\ Bangladesh \\ ${ }^{10}$ Department of Nephrology, Shaheed M. Monsur Ali Medical College, Sirajgonj, Bangladesh \\ Email: *shahidurrahman70@gmail.com
}

\begin{abstract}
How to cite this paper: Shahidur Rahman, A.K.M., Ahsan, M.S., Ahsan, M.K., Mobasher Alam, A.B.M., Rahman, T., Mullah, S., Rahman, Md.M., Feroz, S., Kaiser, A.M. and Haque, Md.S. (2020) Prevalence of Depression in Pre-Dialytic Chronic Kidney Disease Patients Attending at a Tertiary Care Hospital in Bangladesh. Journal of Biosciences and Medicines, 8, 135-148. https://doi.org/10.4236/jbm.2020.812013
\end{abstract}

Received: November 14, 2020 Accepted: December 19, 2020 Published: December 22, 2020

Copyright $\odot 2020$ by author(s) and Scientific Research Publishing Inc. This work is licensed under the Creative Commons Attribution International License (CC BY 4.0).

http://creativecommons.org/licenses/by/4.0/

\begin{abstract}
Background: Depression is a common and serious medical illness around the world. It occurs more frequently in patients with chronic illness than in the general population. It is a common psychiatric problem in patients with chronic kidney disease (CKD). Objective: To assess the level of depression in pre-dialytic CKD patients attending at a tertiary care hospital in Bangladesh. Methodology: This cross sectional study was conducted at Department of Nephrology, Bangabandhu Sheikh Mujib Medical University (BSMMU), Dhaka, Bangladesh from January 2020 to June 2020. A total of 100 pre-dialytic CKD patients were selected by convenience sampling technique and their level of depression was assessed by Zung Self-Rating Depression Scale (ZSDS). Data were collected by existing questionnaire with face to face interview and analyzed by statistical test. Results: The mean age of the participants was $49.70 \pm$ 11.80 years. Among them $64 \%$ were male, $95 \%$ were muslim, $98 \%$ were married, $65 \%$ were completed secondary/above higher secondary level education, $65 \%$ were unemployed and $55 \%$ were lived in urban area. It was observed that $65 \%$ participants were economically dependent to their family, only $6 \%$ were engaged in regular exercise, $14 \%$ had family history of depression, $8 \%$ were
\end{abstract}


smoker and 12\% were alcohol/drug abuser. According to the Zung Self-Rating Depression Scale (ZSDS) we found 29\% participants were mildly depressed, $39 \%$ participants were moderately depressed and $18 \%$ participants were severely depressed. Prevalence of depression was $86 \%$ in pre-dialytic CKD patients. Of them, $7 \%$ was in CKD stage-I, $17.4 \%$ was in CKD stage-II, $19.8 \%$ was in CKD stage-III, $22.1 \%$ was in CKD stage-IV and $33.7 \%$ was in CKD stage-V. Conclusion: Depression is highly prevalent in pre-dialytic CKD patients and more frequent in the advanced stages of CKD.

\section{Keywords}

Chronic Kidney Disease (CKD), Depression, Zung Self-Rating Depression Scale (ZSDS)

\section{Introduction}

Depression is a mental state that affects the mental functioning and thinking process of an individual, greatly diminishing one's social roles and productivity [1]. Symptoms of depression include: depressed mood most of the time, loss of interest in most of the activities, loss of pleasure for most of the time. Other symptoms of depression include: significant weight loss or gain, insomnia/hypersomnia, fatigue, psychomotor agitation or retardation, feeling worthless, excessive guilt, inability to concentrate, thought of death and suicidal tendency [2]. Depression is a disorder of major public health importance, in terms of suffering, dysfunction, morbidity and economic burden [2]. Depression affects people of all ages in all countries. The World Health Organization estimates that depression will become the second most important cause of disability after ischemic heart disease worldwide by 2030 [3].

The neurobiological approaches to etiology of depression postulate that there may be alteration in monoamines receptors as well as in the concentration or the turnover of the amines [4]. There may be a disorder of the hypothalamic center controlling the endocrine system found in patients with depression [4]. Depression occurs more frequently in patients with chronic illness than in the general population [5]. Recent clinical research showed a higher prevalence of depression in the chronic disease patients. The rates vary between the various diagnoses but have been estimated to be $10 \%-40 \%$ [5] [6]. This prevalence rate is 2 to 8 times higher than that in general population [6]. Therefore, understanding the relationship between depression and chronic disease patients is important to assess and manage approaches that are vital in chronic medical illness.

Chronic kidney disease (CKD) is a global health problem equally affecting the people of developed countries as well as developing countries [7]. CKD causes enormous economic losses, and also triggers major challenges in regards to health. CKD patients had an $83 \%$ higher rate of all-causes of mortality [7]. The worldwide prevalence of chronic kidney disease is 7\% - 10\% [8] [9] [10]. CKD is 
the high-stress illness because of the chronicity of the disease and its long-term treatment. People with various stages of CKD experience a high burden of somatic symptoms, impaired quality of life and role impairment that may predispose them to increased risks of depression [11]. Due to the irreversible nature and poorer prognostic outcomes, psychiatric disorders especially depression are common among patients with CKD [7]. The reported prevalence of depression in CKD ranges between $20 \%$ and $30 \%$ compared with $2 \%$ to $4 \%$ in the general population [7] [12]. Recently, a study demonstrated that depression in pre-dialytic CKD patients was linked to a $86 \%$ higher risk of adverse events including death, early dialysis initiation or hospitalization risk; suggesting that depression is a matter of great concern during the routine care of CKD patients [13]. But there is scarce evidence to assess the depression among pre-dialytic CKD patients in Bangladesh. Therefore this study was aimed to evaluate the level of depression in pre-dialytic CKD patients attending at a tertiary care hospital in Bangladesh.

\section{Methodology}

This prospective cross sectional study was conducted at Department of Nephrology, Bangabandhu Sheikh Mujib Medical University (BSMMU), Dhaka, Bangladesh from January 2020 to June 2020. A total of one hundred (100) pre-dialytic chronic kidney disease (CKD) patients were selected as study population following selection criteria by using convenience sampling technique. Sample size was estimated by using, $\mathrm{n}=\mathrm{z}^{2}(\mathrm{p} \times \mathrm{q}) / \mathrm{d}^{2}$ formula; where allowable error $5 \%$ with $95 \%$ confidence level. Assuming $8.7 \%$ prevalence of depression in chronic disease patients [12], the required sample size was 246 . Because it was a single centre study and time constraints, a total of 100 patients were studied. After ethical approval of the study, due permission was taken from the respective authority for data collection. CKD patients attending at the out-patient department of Nephrology, BSMMU were approached for participation in this study. All necessary information was explained to the participants regarding the nature, purpose and objectives of the study along with their rights to the study and asked them to participate in this study. Adult (age $>18$ years) chronic kidney disease (CKD stage-I to stage-V) patients of both sexes were included in this study. CKD patients on maintenance haemodialysis (MHD), renal transplant patients, severe physically ill participants and participants having any types of malignancy along with CKD were excluded from the study. In this study each patient's estimated glomerular filtration rate (e-GFR) was calculated by Cockcoft-Gault (CG) formula, then according to the e-GFR patients were assigned in different stages of CKD using ${ }^{\star}$ KDIGO, 2012 guideline.

\subsection{Definition of Chronic Kidney Disease (CKD)}

According to ${ }^{*}$ KDIGO 2012 Clinical Practice Guideline for the Evaluation and Management of Chronic Kidney Disease, CKD is defined as abnormalities of 
kidney structure or function, present for $>3$ months.

\subsection{Stages of Chronic Kidney Disease (CKD)}

${ }^{*} \mathrm{KDIGO}$ suggested the following stages of CKD.

- Stage 1: normal e-GFR $\geq 90 \mathrm{~mL} /$ minute per $1.73 \mathrm{~m}^{2}$.

- Stage 2: e-GFR between 60 to $89 \mathrm{~mL} /$ minute per $1.73 \mathrm{~m}^{2}$ (mildly decreased renal function).

- Stage 3a: e-GFR between 45 to $59 \mathrm{~mL} /$ minute per $1.73 \mathrm{~m}^{2}$ (Mild to moderately decreased renal function).

- Stage 3b: e-GFR between 30 to $44 \mathrm{~mL} /$ minute per $1.73 \mathrm{~m}^{2}$ (Moderate to severely decreased renal function).

- Stage 4: e-GFR between 15 to $29 \mathrm{~mL} /$ minute per $1.73 \mathrm{~m}^{2}$ (Severely decreased renal function).

- Stage 5: e-GFR of $<15 \mathrm{~mL} /$ minute per $1.73 \mathrm{~m}^{2}$ (Kidney failure). $\left[{ }^{\star} \mathrm{KDIGO}=\right.$ Kidney Disease Improving Global Outcomes $]$.

\subsection{Data Collection Tool}

Two (2) questionnaires were used for data collection. These were Socio-Demographic Data Assessment Questionnaire and Zung Self-Rating Depression Scale (ZSDS).

The Socio-Demographic Data Assessment Questionnaire was used to collect the participant's personal information including: age, gender, marital status, religion, educational qualification, employment status, place of residence, personal history, disease related information etc.

The Zung Self-Rating Depression Scale (ZSDS) was designed by W. W. Zung to assess the level of depression. The ZSDS is widely validated a short self-administered survey to quantify the depressed status of a patient. There are 20 -weighted items on the scale that rate the four common characteristics of depression: the pervasive effect, the physiological equivalents, other disturbances and psychomotor activities. There are ten positively worded and ten negatively worded questions. Each question is scored on a scale of 1 - 4 (a little of the time, some of the time, good part of the time, most of the time). The ZSDS scores range from $20-80$ and the cut off for defining depression is 50 . The score of 50 - 59 indicates mild depression, score 60 - 69 is indicative of moderate depression while score $\geq 70$ is severe depression [14]. The ZSDS questionnaire was translated into Bangla language for patients who did not understand English. This Bangla translation was evaluated by a team comprises of practicing psychiatrist and an expert in English literature whose native language is Bangla.

\subsection{Data Collection Procedure}

Informed written consent was taken from each participant prior to enrollment in the study. Data were collected on questionnaires by face-to-face interview. 
Each participant was requested to response particular questions of the questionnaires. Then screening of the questionnaires to check the completeness of each question was done.

\subsection{Data Analysis}

Data cleaning validation and analysis was performed using the Statistical Package for Social Science (SPSS) version 26.0 software. Categorical data were presented as frequency/percentage and continuous variable was expressed as mean \pm SD (standard deviation). The statistics used to analyze the data were descriptive statistics and Chi-square test was performed. The level of significance was set at 0.05 and a $p$ value $<0.05$ was considered as significant.

\section{Results}

A total of one hundred (100) pre-dialytic chronic kidney disease (CKD) patients participated in this study (Table 1). Their age ranged from 24 to 70 years and mean $( \pm \mathrm{SD})$ age was $49.70 \pm 11.80$ years. The majority $(64 \%)$ of the participants were male and most (95\%) of the participants were Muslim. A large percentage (98\%) of the participants was married. Almost one-third of the study participants (31\%) had secondary level education and another one-third (34\%) had higher secondary and above level education. The data also revealed that $65 \%$ of the study participants were unemployed and among the employed (35\%) participants $40 \%$ were service-holder, $14.3 \%$ were businessmen, $45.7 \%$ were engaged in other occupations. Regarding the place of residence, more than half (55\%) of the participants were lived in urban areas.

It was observed that $65 \%$ participants were economically dependent to their family, only $6 \%$ were engaged in regular exercise, $14 \%$ had family history of depression, $8 \%$ were smoker and $12 \%$ were alcohol/drug abuser (Table 2).

According to ${ }^{\star} \mathrm{KDIGO} 2012$ Guideline, among total 100 pre-dialytic CKD patients; 8 were in CKD stage-I, 18 were in CKD stage-II, 24 were in CKD stage-III, 21 were in CKD stage-IV and 29 were in CKD stage-V (Table 3).

On the basis of Zung Self-Rating Depression Scale (ZSDS) we found 29\% participants were mildly depressed, 39\% participants were moderately depressed, $18 \%$ participants were severely depressed and $14 \%$ participants had no depression. The mean Zung score of the study participants was 58.9 ( \pm 9.54$)$ (Table 4).

There was no significant association between the severity of depression in pre-dialytic CKD patients with different socio-demographic parameters like-age group, gender, religious belief, marital status, level of educational, employment status and place of residence ( $p>0.05)$ (Table 5).

No significant association was observed between depression in pre-dialytic CKD patients with their personal characteristics like-economic dependency, regular exercise, family history of depression, smoking habit and alcohol/drug abuse $(\mathrm{p}>0.05)$ (Table 6).

In this study depression was observed in 86 pre-dialytic CKD patients among 
Table 1. Basic data of the study patients $(\mathrm{N}=100)$.

\begin{tabular}{|c|c|c|}
\hline Variables & Frequency & Percentage (\%) \\
\hline \multicolumn{3}{|l|}{ Age group (years) } \\
\hline $20-30$ & 7 & 7.0 \\
\hline $31-40$ & 24 & 24.0 \\
\hline $41-50$ & 23 & 23.0 \\
\hline $51-60$ & 33 & 33.0 \\
\hline $61-70$ & 13 & 13.0 \\
\hline Mean \pm SD & \multicolumn{2}{|c|}{$49.70 \pm 11.80$} \\
\hline Range & \multicolumn{2}{|c|}{$(24-70)$ years } \\
\hline \multicolumn{3}{|l|}{ Gender } \\
\hline Male & 64 & 64.0 \\
\hline Female & 36 & 36.0 \\
\hline Male:Female ratio & \multicolumn{2}{|c|}{$1.8: 1$} \\
\hline \multicolumn{3}{|l|}{ Religion } \\
\hline Muslim & 95 & 95.0 \\
\hline Hindu & 5 & 5.0 \\
\hline \multicolumn{3}{|l|}{ Marital status } \\
\hline Married & 98 & 98.0 \\
\hline Unmarried & 1 & 1.0 \\
\hline Widow & 1 & 1.0 \\
\hline \multicolumn{3}{|l|}{ Educational status } \\
\hline Illiterate & 18 & 18.0 \\
\hline Primary & 17 & 17.0 \\
\hline Secondary & 31 & 31.0 \\
\hline Higher secondary and above & 34 & 34.0 \\
\hline \multicolumn{3}{|l|}{ Employment status } \\
\hline Employed & 35 & 35.0 \\
\hline Service & 14 & 40.0 \\
\hline Business & 5 & 14.3 \\
\hline Others & 16 & 45.7 \\
\hline Unemployed & 65 & 65.0 \\
\hline \multicolumn{3}{|l|}{ Place of residence } \\
\hline Urban & 55 & 55.0 \\
\hline Rural & 45 & 45.0 \\
\hline
\end{tabular}

Table 2. Distribution of the study patients by personal characteristics $(\mathrm{N}=100)$.

\begin{tabular}{ccc}
\hline Variables & Frequency & Percentage (\%) \\
\hline Economically dependent & 65 & 65.0 \\
Regular exercise & 6 & 6.0 \\
Family history of depression & 14 & 14.0 \\
Smoking habit & 8 & 8.0 \\
Alcohol/drug abuse & 12 & 12.0
\end{tabular}


Table 3. Distribution of the study patients by CKD stages $(\mathrm{N}=100)$.

\begin{tabular}{ccc}
\hline CKD stage & Frequency & Percentage (\%) \\
\hline Stage-I & 8 & 8.0 \\
Stage-II & 18 & 18.0 \\
Stage-III & 24 & 24.0 \\
Stage-IV & 21 & 21.0 \\
Stage-V & 29 & 29.0 \\
Total & 100 & 100.0 \\
\hline
\end{tabular}

Table 4. Distribution of the study patients by severity of depression $(\mathrm{N}=100)$.

\begin{tabular}{ccc}
\hline Severity of depression & Frequency & Percentage (\%) \\
\hline Normal $(20-49)$ & 14 & 14.0 \\
Mildly depressed $(50-59)$ & 29 & 29.0 \\
Moderately depressed $(60-69)$ & 39 & 39.0 \\
Severely depressed (>70) & 18 & 18.0 \\
Total & 100 & 100.0 \\
Mean Zung score ( \pm SD) & & $58.9 \pm 9.54$ \\
\hline
\end{tabular}

total 100 pre-dialytic CKD patients. Therefore depression was prevalent in $86 \%$ pre-dialytic CKD patients. Of them $7.0 \%$ was in CKD stage-I, $17.4 \%$ was in CKD stage-II, 19.8\% was in CKD stage-III, 22.1\% was in CKD stage-IV and $33.7 .0 \%$ was in CKD stage- $\mathrm{V}$ respectively. It has been observed that depression was significantly more frequent in the advanced stages of CKD $(p=0.032)($ Table 7$)$.

\section{Discussion}

Depression is becoming a very important issue in modern society. It is more frequent in patients with chronic illnesses than in the general population. Due to the irreversible nature and poorer prognostic outcomes, depression is frequently common among patients with chronic kidney disease (CKD). The current study aimed to identify the depression of pre-dialytic CKD patients at a tertiary care hospital in Bangladesh. A total of 100 pre-dialytic CKD patients were enrolled in this study. Their age ranged from 24 to 70 years, with the mean age of $49.70 \pm$ 11.80 years. A couple of similar studies found the mean age of CKD patients was $43.6 \pm 15.1$ years [15] and $46.55 \pm 12.09$ years [16], which were consistent with this current study. Although, our finding was inconsistent with the study carried out in Taiwan which revealed that the mean age of participants' was $65.70 \pm$ 12.37 years [17]. The majority (64\%) of the participants were male and this finding was consistent with related previous studies as reported that male participants were $61.9 \%$ [15], 69.6\% [18] and 52\% [19]. Most of our participants (98\%) were married, in accordance Chiang et al. [17] found 93\% married in their study population. While Uzzal, et al. [18] found 7.9\% married subjects suffering depression in their 275 study population, that finding was different from our study. 
Table 5. Association of depression of pre-dialytic CKD patients with different socio-demographic parameters $(\mathrm{N}=100)$.

\begin{tabular}{|c|c|c|c|}
\hline \multirow[b]{2}{*}{ Variables } & \multicolumn{2}{|c|}{ Depression } & \multirow[b]{2}{*}{ p-value } \\
\hline & $\begin{array}{l}\text { Present } \\
(\mathrm{n}=86) \\
\text { No. }(\%)\end{array}$ & $\begin{array}{l}\text { Absent } \\
(\mathrm{n}=14) \\
\text { No. }(\%)\end{array}$ & \\
\hline \multicolumn{4}{|l|}{ Age group (years) } \\
\hline $20-30$ & $5(5.8 \%)$ & $2(14.3 \%)$ & \multirow{5}{*}{0.471} \\
\hline $31-40$ & $22(25.6 \%)$ & $2(14.3 \%)$ & \\
\hline $41-50$ & $18(20.9 \%)$ & $5(35.7 \%)$ & \\
\hline $51-60$ & $29(33.7 \%)$ & $4(28.6 \%)$ & \\
\hline $61-70$ & $12(14.0 \%)$ & $1(7.1 \%)$ & \\
\hline \multicolumn{4}{|l|}{ Gender } \\
\hline Male & $57(66.3 \%)$ & $7(50.0 \%)$ & \multirow{2}{*}{0.239} \\
\hline Female & $29(33.7 \%)$ & $7(50.0 \%)$ & \\
\hline Male: Female ratio & $1.9: 1$ & $1: 1$ & \\
\hline \multicolumn{4}{|l|}{ Religion } \\
\hline Muslim & $82(95.3 \%)$ & $13(92.9 \%)$ & \multirow{2}{*}{0.692} \\
\hline Hindu & $4(4.7 \%)$ & $1(7.1 \%)$ & \\
\hline \multicolumn{4}{|l|}{ Marital status } \\
\hline Married & $84(97.7 \%)$ & $14(100.0 \%)$ & \multirow{3}{*}{0.847} \\
\hline Unmarried & $1(1.2 \%)$ & $0(0.0 \%)$ & \\
\hline Widow & $1(1.2 \%)$ & $0(0.0 \%)$ & \\
\hline \multicolumn{4}{|l|}{ Level of educational } \\
\hline Illiterate & $14(16.3 \%)$ & $4(28.6 \%)$ & \multirow{4}{*}{0.582} \\
\hline Primary & $15(17.4 \%)$ & $2(14.3 \%)$ & \\
\hline Secondary & $26(30.2 \%)$ & $5(35.7 \%)$ & \\
\hline Higher secondary above & $31(36.0 \%)$ & $3(21.4 \%)$ & \\
\hline \multicolumn{4}{|l|}{ Employment status } \\
\hline Employed & $29(33.7 \%)$ & $6(42.9 \%)$ & \multirow{2}{*}{0.506} \\
\hline Unemployed & $57(66.0 \%)$ & $8(57.1 \%)$ & \\
\hline \multicolumn{4}{|l|}{ Place of residence } \\
\hline Urban & $48(55.8 \%)$ & $7(50.0 \%)$ & \multirow{2}{*}{0.685} \\
\hline Rural & $38(44.2 \%)$ & $7(50.0 \%)$ & \\
\hline
\end{tabular}

Chi-square test was used to analyze data.

In our study more than half (65\%) of the study participants had secondary/higher secondary and above level education, in this series one third (33.2\%) of the study patients were illiterate and half (50.3\%) of them had education up to secondary school level as showed by Uzzal et al. [18]; while Chiang et al. [17] observed $74.8 \%$ had a low level of education in their study population. The data of our study also reveals that almost two-third (65\%) of the participants were unemployed. In this context, Uzzal, et al. [18] reported that about three-fourth of their study patients (72.2\%) were unemployed. More than half (55\%) of our 
Table 6. Association of depression in pre-dialytic CKD patients with their personal characteristics $(\mathrm{N}=100)$.

\begin{tabular}{|c|c|c|c|}
\hline \multirow[b]{2}{*}{ Variables } & \multicolumn{2}{|c|}{ Depression } & \multirow[b]{2}{*}{ p-value } \\
\hline & $\begin{array}{l}\text { Present } \\
(n=86) \\
\text { No. }(\%)\end{array}$ & $\begin{array}{c}\text { Absent } \\
(\mathrm{n}=14) \\
\text { No. }(\%)\end{array}$ & \\
\hline \multicolumn{4}{|c|}{ Economic dependency } \\
\hline Dependent & $55(64.0 \%)$ & $10(71.4 \%)$ & \multirow{2}{*}{0.587} \\
\hline Independent & $31(36.0 \%)$ & $4(28.6 \%)$ & \\
\hline \multicolumn{4}{|c|}{ Regular exercise } \\
\hline Yes & $5(5.8 \%)$ & $1(7.1 \%)$ & \multirow{2}{*}{0.846} \\
\hline No & $81(94.2 \%)$ & $13(92.9 \%)$ & \\
\hline \multicolumn{4}{|c|}{ Family history of depression } \\
\hline Yes & $14(16.3 \%)$ & $0(0.0 \%)$ & \multirow{2}{*}{0.104} \\
\hline No & $72(83.7 \%)$ & $14(100.0 \%)$ & \\
\hline \multicolumn{4}{|l|}{ Smoking habit } \\
\hline Yes & $8(9.3 \%)$ & $0(0.0 \%)$ & \multirow{2}{*}{0.234} \\
\hline No & $78(90.7 \%)$ & $14(100.0 \%)$ & \\
\hline \multicolumn{4}{|c|}{ Alcohol/drug abuse } \\
\hline Yes & $9(10.5 \%)$ & $3(21.4 \%)$ & \multirow{2}{*}{0.242} \\
\hline No & $77(89.5 \%)$ & $11(78.6 \%)$ & \\
\hline
\end{tabular}

Chi-square test was used to analyze data.

Table 7. Association of depression of pre-dialytic CKD patients with $\mathrm{CKD}$ stages $(\mathrm{N}=$ 100).

\begin{tabular}{cccc}
\hline & \multicolumn{2}{c}{ Depression } & \\
\cline { 2 - 3 } CKD stage & $\begin{array}{c}\text { Present } \\
(\mathbf{n}=86)\end{array}$ & $\begin{array}{c}\text { Absent } \\
\text { No. }(\%)\end{array}$ & p-value \\
& No. $(\%)$ & \\
\hline Stage-I & $6(7.0 \%)$ & $2(14.3 \%)$ & \\
Stage-II & $15(17.4 \%)$ & $3(21.4 \%)$ & \\
Stage-III & $17(19.8 \%)$ & $7(50.0 \%)$ & $0.032^{\text {s }}$ \\
Stage-IV & $19(22.1 \%)$ & $2(14.3 \%)$ & \\
Stage-V & $29(33.7 \%)$ & $0(0.0 \%)$ & \\
Total & $86(100.0 \%)$ & $14(100.0 \%)$ & \\
\hline
\end{tabular}

Chi-square test was used to analyze data, $s=$ significant.

study participants lived in urban area, in accordance Uzzal et al. [18] observed that most of their study patients (64.9\%) lived in urban area.

Several studies around the world have been performed to determine the validity and optimal cut-off scores for depression using different screening tools. In this study the level of depression was assessed by the Zung self rating depression scale (ZSDS). In present study the mean Zung score of the study participants was 58.9 ( \pm 9.54$)$, depression was observed in $86 \%$ pre-dialytic CKD patients and we 
found that depression was more frequent in the advanced stages of CKD. These findings were consistent with similar previous studies [16] [18] [20] [21]. The possible reason for more depression in pre-dialytic CKD patients may be due to the emotional reaction to the disease and inability to afford treatment expenditure. Our data revealed that, $29 \%$ participants have mild depression, $39 \%$ have moderate depression, $18 \%$ have severe depression and only $14 \%$ have no depression among total100 study participants. Similar previous study showed that; mild depression was $32.3 \%$, moderate depression was $50.0 \%$ and severe depression was $8.6 \%$ among total $266 \mathrm{CKD}$ patients [16]. Another related study reported that mild, moderate and severe depression among $226 \mathrm{CKD}$ patients were $28.3 \%, 25.6 \%$ and $7.96 \%$ respectively [21]. The results of the current study were partially supported by the findings of these previous studies.

Different studies across the world on depression in CKD patients showed different results regarding socio-demographic variables. In this study total score of the ZSDS was not associated with different variables of socio-demographic characteristics in pre-dialytic CKD patients. These findings were not comparable with previous studies and possible explanation could be the ethnic diversity [17] [19] [22]. On the other hand, in present study we didn't find any association between depression in CKD patients with their economic dependency, regular exercise, family history of depression, smoking habit and alcohol/drug abuse. These results were consistent with a similar previous study [18].

This study demonstrated that depression is frequently prevalent in pre-dialytic CKD patients. This could be due to a lot of contributory factors which may range from emotional reaction to the diagnosis of disease to the treatment modalities, as well as losses experienced in terms of health and finances of the patient. An early diagnosis and proper treatment of depression in pre-dialytic CKD patients could improve their quality of life.

\section{Conclusion}

This study concluded that depression is highly prevalent in pre-dialytic CKD patients and more frequent in the advanced stages of CKD. The findings of this study might be helpful for professionals to evaluate the pre-dialytic CKD patients in psychological background.

\section{Recommendations}

A population based multi-center study with large sample size should be done for better evaluation of depression in pre-dialytic CKD patients.

\section{Limitations of the Study}

It was a single center study with a relatively small sample size.

\section{Conflicts of Interest}

The authors declare no conflicts of interest regarding the publication of this paper. 


\section{References}

[1] Roehr, B. (2013) American Psychiatric Association Explains DSM-5. BMJ, 346, f3591. https://doi.org/10.1136/bmj.f3591

[2] Lopez, A.D., Mathers, C.D., Ezzati, M., Jamison, D.T. and Murray, C.J. (2006) Global Burden of Disease and Risk Factors. The World Bank, Washington DC. https://doi.org/10.1596/978-0-8213-6262-4

[3] Lépine, J.P. and Briley, M. (2011) The Increasing Burden of Depression. Neuropsychiatric Disease and Treatment, 7, 3. https://doi.org/10.2147/NDT.S19617

[4] Gelder, M.G., Cowen, P. and Harrison, P.J. (2006) Shorter Oxford Textbook of Psychiatry. Oxford University Press, Oxford.

[5] Sabaté, E. and Sabaté, E. (2003) Adherence to Long-Term Therapies: Evidence for Action. World Health Organization, Geneva.

[6] Chowdhury, N.N., Sobhan, M.A., Mullick, M.S., Khanam, M., Nahar, J.S., Salam, M.A., Chowdhury, N.S., Islam, H. and Islam, T. (2006) Psychiatric Disorder in Chronic Physical Illness. Bangladesh Journal of Psychiatry, 20, 87-94.

[7] Wen, C.P., Cheng, T.Y., Tsai, M.K., Chang, Y.C., Chan, H.T., Tsai, S.P., Chiang, P.H., Hsu, C.C., Sung, P.K., Hsu, Y.H. and Wen, S.F. (2008) All-Cause Mortality Attributable to Chronic Kidney Disease: A Prospective Cohort Study Based on 462 293 Adults in Taiwan. The Lancet, 371, 2173-2182. https://doi.org/10.1016/S0140-6736(08)60952-6

[8] Coresh, J., Selvin, E., Stevens, L.A., Manzi, J., Kusek, J.W., Eggers, P., Van Lente, F. and Levey, A.S. (2007) Prevalence of Chronic Kidney Disease in the United States. JAMA, 298, 2038-2047. https://doi.org/10.1001/jama.298.17.2038

[9] Chan, R., Brooks, R., Erlich, J., Chow, J. and Suranyi, M. (2009) The Effects of Kidney-Disease-Related Loss on Long-Term Dialysis Patients' Depression and Quality of Life: Positive Affect as a Mediator. Clinical Journal of the American Society of Nephrology, 4, 160-167. https://doi.org/10.2215/CJN.01520308

[10] Shan, Y., Zhang, Q., Liu, Z., Hu, X. and Liu, D. (2010) Prevalence and Risk Factors Associated with Chronic Kidney Disease in Adults over 40 Years: A Population Study from Central China. Nephrology, 15, 354-361.

https://doi.org/10.1111/j.1440-1797.2009.01249.x

[11] Hassanien, A.A., Al-Shaikh, F., Vamos, E.P., Yadegarfar, G. and Majeed, A. (2012) Epidemiology of End-Stage Renal Disease in the Countries of the Gulf Cooperation Council: A Systematic Review. JRSM Short Reports, 3, 1-21.

https://doi.org/10.1258/shorts.2012.011150

[12] Hedayati, S.S. and Finkelstein, F.O. (2009) Epidemiology, Diagnosis, and Management of Depression in Patients with CKD. American Journal of Kidney Diseases, 54, 741-752. https://doi.org/10.1053/j.ajkd.2009.05.003

[13] Hedayati, S.S. and Finkelstein, F.O. (2009) DSM-IV Criteria for Major Depressive Episode: Symptom Domains. American Journal of Kidney Diseases, 4, 741-752. https://doi.org/10.1053/j.ajkd.2009.03.017

[14] Zung, W.W., Richards, C.B. and Short, M.J. (1965) Self-Rating Depression Scale in an Outpatient Clinic: Further Validation of the SDS. Archives of General Psychiatry, 13, 508-515. https://doi.org/10.1001/archpsyc.1965.01730060026004

[15] Amira, O. (2011) Prevalence of Symptoms of Depression among Patients with Chronic Kidney Disease. Nigerian Journal of Clinical Practice, 14, 460-463. https://doi.org/10.4103/1119-3077.91756

[16] AlDukhayel, A. (2015) Prevalence of Depressive Symptoms among Hemodialysis 
and Peritoneal Dialysis Patients. International Journal of Health Sciences, 9, 9-16. https://doi.org/10.12816/0024678

[17] Chiang, H.H., Livneh, H., Yen, M.L., Li, T.C. and Tsai, T.Y. (2013) Prevalence and Correlates of Depression among Chronic Kidney Disease Patients in Taiwan. BMC Nephrology, 14, 78. https://doi.org/10.1186/1471-2369-14-78

[18] Uzzal, O.K., Islam, M.N., Ahmed, P.I., Al Mamun, M.A., Hossain, M.B., Bhuiyan, F.K. and Khan, M.F. (2015) Depression and Insomnia in Patients on Maintenance Hemodialysis. Journal of Dhaka Medical College, 24, 3-11. https://doi.org/10.3329/jdmc.v24i1.29555

[19] Kokoszka, A., Leszczyńska, K., Radzio, R., Daniewska, D., Łukasiewicz, A., Orzechowski, W.M., Piskorz, A. and Gellert, R. (2016) Prevalence of Depressive and Anxiety Disorders in Dialysis Patients with Chronic Kidney Disease. Archives of Psychiatry and Psychotherapy, 1, 8-13. https://doi.org/10.12740/APP/61977

[20] Thomas, R., Acharya, S. and Shukl, S. (2014) Prevalance of Depression among Patients with Chronic Kidney. IOSR Journal of Dental and Medical Sciences, 13, 19-22. https://doi.org/10.9790/0853-13951922

[21] Hawamdeh, S., Almari, A.M., Almutairi, A.S. and Dator, W.L. (2017) Determinants and Prevalence of Depression in Patients with Chronic Renal Disease, and Their Caregivers. International Journal of Nephrology and Renovascular Disease, 10, 183. https://doi.org/10.2147/IJNRD.S139652

[22] Shirazian, S., Grant, C.D., Aina, O., Mattana, J., Khorassani, F. and Ricardo, A.C. (2017) Depression in Chronic Kidney Disease and End-Stage Renal Disease: Similarities and Differences in Diagnosis, Epidemiology, and Management. Kidney International Reports, 2, 94-107. https://doi.org/10.1016/j.ekir.2016.09.005 


\section{Questionnaire (English Version)}

\section{Research Title: Prevalence of Depression in Pre-Dialytic Chronic Kidney} Disease Patients Attending at a Tertiary Care Hospital in Bangladesh.

These questionnaires are to identify the prevalence of depression among pre-dialytic chronic kidney disease patients. There are two parts of the questionnaire, including.

1) Part I: Socio-Demographic, Personal history \& Disease Related Questionnaire.

2) Part II: Zung-Self Rating Depression Scale (ZSDS).

PART-1:

Date \& time

ID NO

Instructions

This questionnaire aims to obtain information about current general data consist of socio-demographic data, personal history and disease related information. Researcher will fillup the data by interviewing the participant individually. The participant is ensured that all information will be kept confidential and will be used only for research purpose. There will be no name use in this questionnaire.

\section{a. Socio-demographic characteristics of participant}

Please tick $(\sqrt{ })$ the relevant number for any option chosen and written in the space providing for the answers.

1. Age (years)

2. Gender

1. Male 2. Female

3. Religion

1. Muslim

2. Hindu

3. Christian

4. Buddhists

4. Marital status 1. Married

2. Unmarried

3. Divorced

4. widows

5. Educational level

1. Illiterate

2. Primary

3. Secondary

4. Higher

Secondary and above

$\begin{array}{ll}\text { 6. Employment status 1. Employed } & \text { 2. Unemployed }\end{array}$

7. Occupation (If employed) 1. Service 2. Business 3. Student4. Others

8. Place of Residence

1. Urban 2. Rural

b. Personal history:

1. Economically dependence to others

$\begin{array}{ll}\text { 1. Dependent } & \text { 2. Independent }\end{array}$

2. Regular exercise

1. Yes

2. No

3. Smoking habit

1. Yes

2. No

4. Drug abuser

1. Yes

2. No

c. Disease related information:

1. Family history of depression

$$
\text { 1. Yes No }
$$

2. CKD-Stages

$$
\begin{aligned}
& \text { 1. Stage-I } \\
& \text { 4. Stage-IV }
\end{aligned}
$$

2. Stage-II

3. Stage-III

5. Stage- $\mathrm{V}$

PART-II: Zung Self-Rating Depression Scale (ZSDS)

For each item below, please place a check mark $(\sqrt{ })$ in the column which best describes how often you felt or behaved this way during the past several days. 


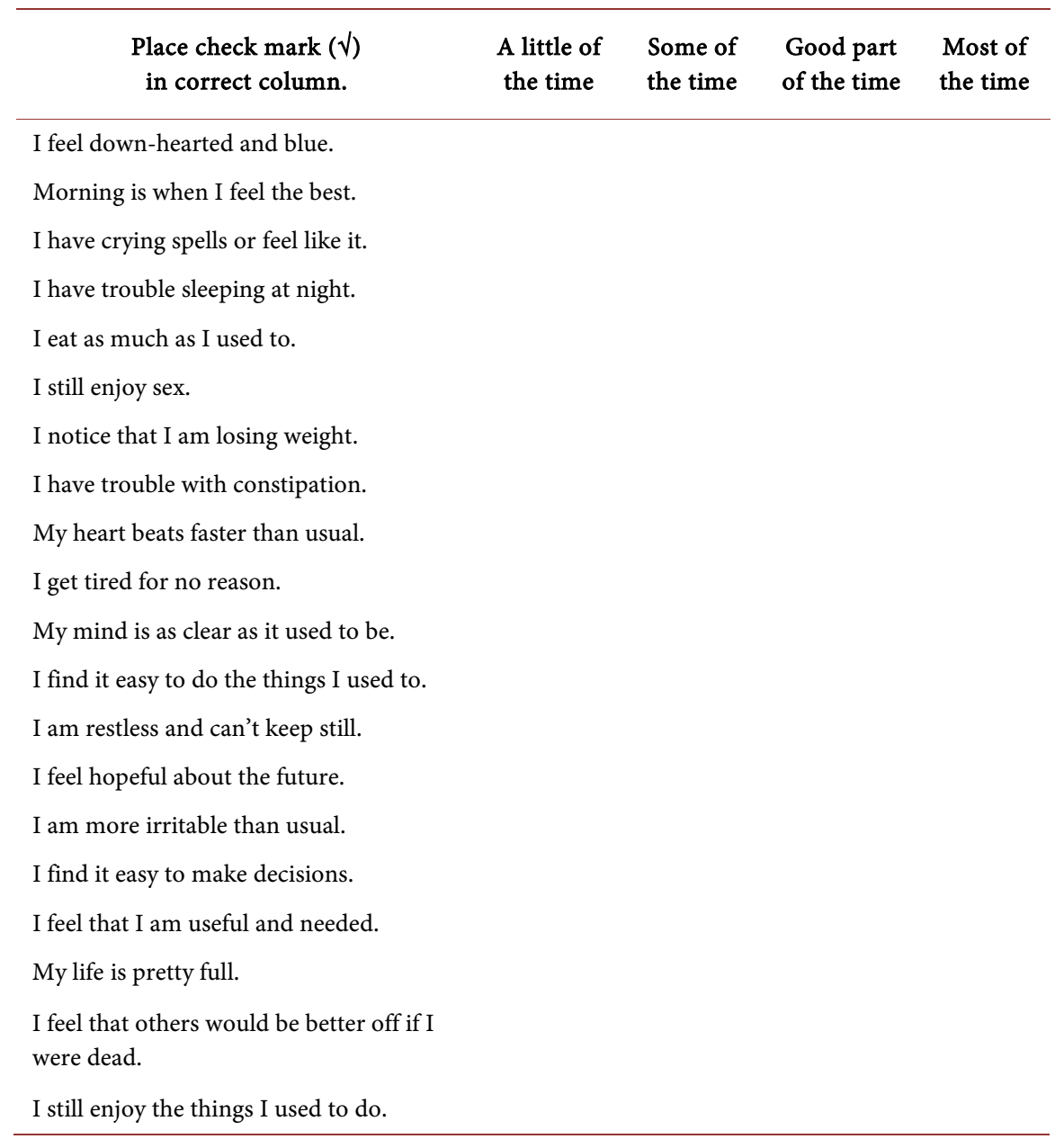

